\title{
Desalination Alternative Technology in Conjunction with Membrane Capacitive Deionization (MCDI): A Literature Review Article
}

\author{
Ahmed J. Aldalou1, Yunes K. Mogheir ${ }^{2}$ \\ ${ }^{1}$ Water Technology PhD Program, Islamic University of Gaza \& AL-Azhar University, Gaza, Palestine \\ ${ }^{2}$ Civil and Environmental Engineering Department, Islamic University of Gaza, Gaza, Palestine \\ Email: adalougrc@gmail.com, aaldalou@students.iugaza.edu.ps
}

How to cite this paper: Aldalou, A.J. and Mogheir, Y.K. (2021) Desalination Alternative Technology in Conjunction with Membrane Capacitive Deionization (MCDI): A Literature Review Article. Journal of Environmental Protection, 12, 218-236. https://doi.org/10.4236/jep.2021.123014

Received: February 12, 2021

Accepted: March 23, 2021

Published: March 26, 2021

\section{Copyright $\odot 2021$ by author(s) and} Scientific Research Publishing Inc. This work is licensed under the Creative Commons Attribution International License (CC BY 4.0).

http://creativecommons.org/licenses/by/4.0/

\begin{abstract}
Water and energy shortages came due to rapid population growth, living standards and rapid development in the agriculture and industrial sectors. Desalination tends to be one of the most promising water solutions; however, it is a process of intense energy. Membrane Capacitive Deionization (MCDI) has received considerable interest as a promising desalination technology, and MCDI research has increased significantly over the last 10 years. In addition, there are no guidelines for the design of Capacitive Deionization (CDI) implementation strategies for individual applications. This study, therefore; provides an alternative of CDI's recent application developments, with emphasis placed on hybrid systems to address the technological needs of different relevant fields. The MCDI's energy consumption is compared with the reverse osmosis literature data based on experimental data from laboratory-scale system. The study demonstrates that MCDI technology is a promising technology in the next few years with an extreme competition in water recovery, energy consumption and salt removal for reverse osmosis.
\end{abstract}

\section{Keywords}

Capacity Deionization, Membrane Capacitive Deionization, Desalination, Reverse Osmosis (RO)

\section{Introduction}

Capacitive Deionization (CDI) and Capacitive Deionization Technology (MCDI) activities have grown exponentially in recent years [1]. Capacitive deionization 
(CDI) is a technique of desalination using a voltage between porous electrodes to de-iconize ions cyclique from the water solution [2]. Water can be stored temporarily in the spacing compartment between the opposite charged electrodes and the ions removed from feed-water at the electrode-water interface. The electrons must be regenerated and the applied voltage decreased or even reversed while the electrodes are filled with an ion. Once the ions are released from the electrodes, the ion can be removed from its junction, resulting in a concentrated ionic waste stream. The process will eliminate ions from the water supply again after electrode regeneration. Recently, the field of desalination has received major interest in CDI, which is also known as electro-sorption, due to its lower energy consumption and simplicity of the environment compared to conventional desalination technologies, such as; reverse osmosis, distillation, and electrical globalization [3]. A common purpose of current research is to increase the efficiency and cost-effectiveness of these technologies, for both deionization of seawater and brackish water. Considering that there are more brackish waters in the world than freshwaters, it is evident that the use of a large amount of brackish water for human and domestic use, agriculture and industry is particularly attractive [4]. Although, major changes have been made in desalination technology, by reducing the energy consumption and/or membrane fouling, during this research, the author focuses on possible further applications, including desalination of the seawater, of the MCDI operating system. In conjunction with MCDI technology, this application is combined with hybrid systems, solar photovoltaics (PV), MCDI as the second desalination systems and other desalination systems to meet technical requirements from various fields of concern. Meanwhile, MCDI technology finds the desalination of brackish water to be highly recommended, with high efficiency in the water recovery, the removal of salt and the reduction of energy consumption. In the context of this study, the main objectives of this study are to review and evaluate alternative possibilities with the most recent application of proven and visible MCDI technology for both brackish and seawater, with the following objectives:

- General description of innovative technologies related to the MCDI capacitive membrane system.

- Present the alternative of MCDI technology in conjunction with multiple desalination plants based on three new technologies [5]:

1) MCDI second Pass for Seawater Desalination,

2) Integration MCDI with Photovoltaic (PV)-Solar energy for salt removal from brackish waters,

3) MCDI-reverse electrodialysis (RED) hybrid system for RO seawater desalination.

- Applying the latest material produced to enhance the productivity of the MCDI to develop a Large-scale unit, with high saline water.

- Inspects the applications of MCDI system in the future.

- Drawing up practical design guidelines for MCDI electrode bulk water 
treatment.

- Provides a summary of CDI's recent developments with emphasis placed on hybrid systems to address the technological needs of different relevant fields.

- Conclude the possibility of factors affecting the energy and water recovery of the desalination system.

- The MCDI's energy consumption will compare with the reverse osmosis literature data based on experimental data from laboratory-scale system.

The study, introduces the main basics data relevant to the capacitive deionization technology (MCDI), with historical and technical context for overall of the system. The study represents the prospect of using the MCDI technology focusing on the current and future application for desalination application. The continuing difficulties in designing and integrating different CDI's, and the potential to enhance cell design, are addressed. The potential insights on current developments in different CDI cell architectures are also presented.

\section{Historical Background of CDI Technology}

Several proven technologies have been in place for decades in seawater desalination, such as; reverse osmosis (RO), electrodialysis distillation (ED), multistage distillation (MED), and flash desalination known as multi-stage desalination (MSF). Nevertheless, the technologies described above may be less suitable for brackish desalination in terms of energy efficiency [6]. New technologies such as forward osmosis, microporous ion concentration polarization and capacitive deionization have been developed for the use of renewable energy sources such; solar and wind energy resources to provide energy savings options [7].

In the early 1960s, Blair, Murphy, and his colleagues worked as pioneers in the theory of water desalination, known at that time as "electrochemical desalination of water." During this time, electrodes were known as "ion representatives" and ions were considered to have been extracted only by reducing or oxidizing a particular surface chemical group, and an ion bond was formed between the ion in solution and the ionized group on the surface of the $\mathrm{CO}_{2}$ the next step sets out the basic conditions for the ionization of the weak hydroxyl ion groups followed by the demineralization cycle. The voltage was re-inversed during the regeneration process, in order to reduce the local $\mathrm{pH}$, and thus; free the previously removed ions. Conventional perspectives on the fundamental principles of pore electrodes' desalination are now outdated and can be summarized briefly as follows: The most important effect is the capacitive concentration of ions in the double electrical layer, and the carbon electrodes are ideal therefore. A brief summary of CDI scientific development schedule showing achievements since the CDI was established in 1960 (Figure 1). Furthermore, in the last two decades the research interest in CDI technology grew rapidly with many CDI cell architectures constantly developing leading to major developments in the area of CDI [8]. Carbon aerogels are considered to be an enhancement on conventional carbon-fired systems due to advances in the monolithic design of carbon aerogels, 


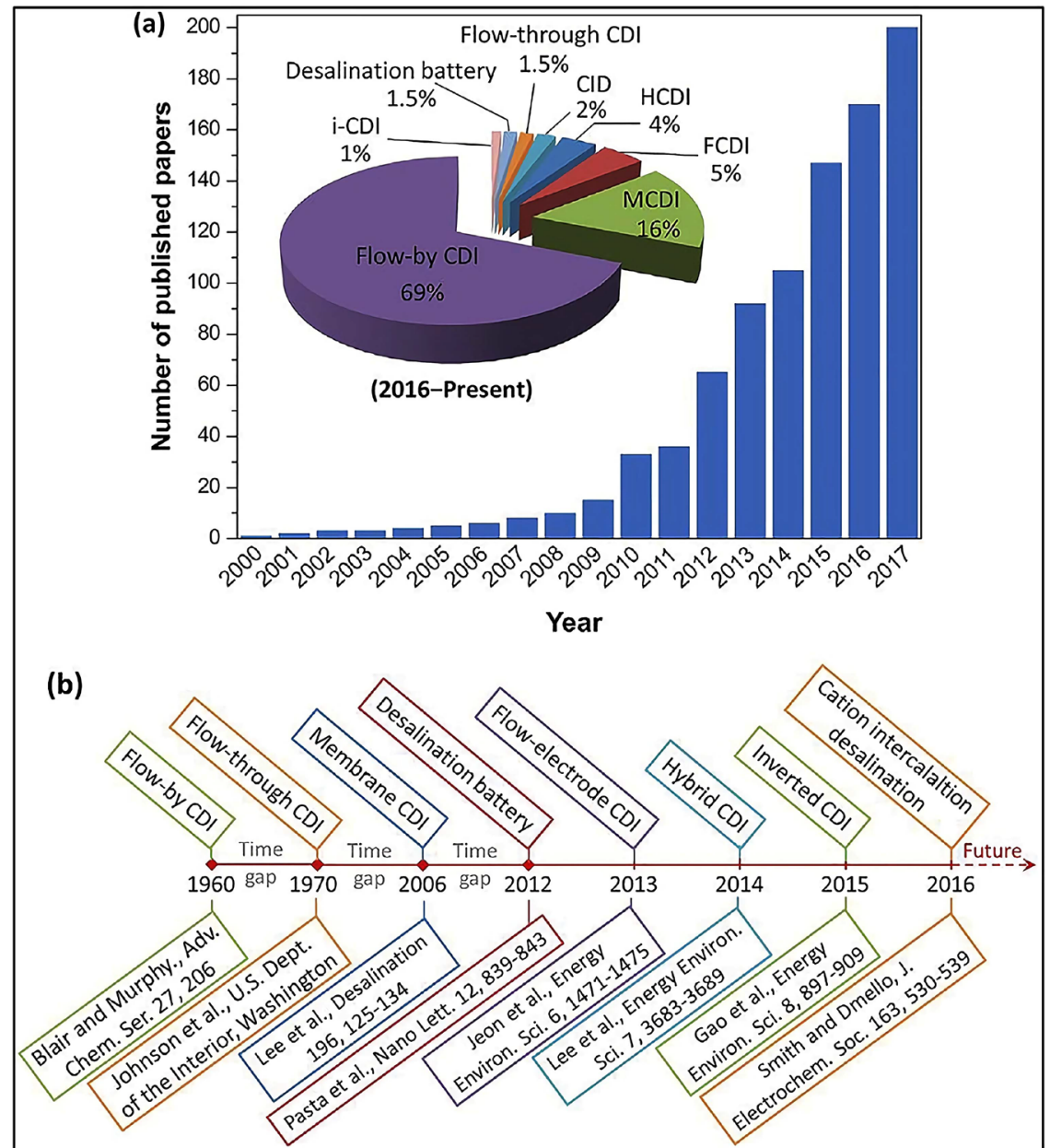

Figure 1. (a) Evolution of the number of publications concerning CDI since the year 2000. The insert pie graph exhibits the percentage of the scientific reports of various CDI cell architectures from 2016 to the present. The data comes from "Web of Science". (b) Timeline displaying the years when various CDI cell architectures emerged and the corresponding seminal work [8].

large interior surfaces, and good conductivity [9]. Further studies on the applications of carbon aerogels for the removal of various salts, e.g. $\mathrm{NaNO}_{3}$, and recent studies are performing new advances in the application of CDI carbon materials.

In the past few years, an essential development of the CDI; consists of an ion-exchange membrane on either side of the electrode separator, with an anion-exchange membrane adjacent to the anode, and the corresponding cathode ion-exchange membrane. Capacitive deionization membrane (MCDI) results in increased membranes which enables the counter-ion transport to the electrode from the spacer channel while avoiding co-ions leaving the electrical field, thus increasing ion inventory in the electrode macropore and boosting the load efficiency [1].

\section{Conceptual Approaches to the CDI Phenomenon}

This section discusses different concepts for describing CDI performance. In this 
regard, two questions regarding are: 1) How to understand the basic phenomenon of the salt adsorption of porous electrodes using external voltage? 2) What is the best structure for theoretical modeling of CDI experimental data quantification? The method is based on a general electrochemical process overview, describing the behavior and output of a CDI cell by pore-carbon electrical appliances, referring to the importance of placing the potential of each electrode in an appropriate manner in relation to, or in a voltage window, required to optimize ion adsorption and a minimum of Faradaic, parasitic electrodes. Alternatively, ion adsorption is not balanced if the potential is not selected correctly. Since the optimum electrode potential depends on the zero-load potential (PZC) of the material, PZC modifications, for example, may increase the resulting CDI output by oxidizing or reducing carbon materials. This can be achieved by reducing the positive electrode in such a way that it negatively changes its PZC, and that the negative electrode can be oxidized to change its PZC positively [4]. Thus, the two electrical codes are worked in one voltage window after applying an electrical difference to a previously short circuit CDI device, where there is minimal co-ion displacement, and predominant counterion adsorption due to potential changes in both electrodes in the opposite direction. All electrodes can also increase electrical power by using a third electrode (reference electrode) which can lead to increased load efficiency and salt adsorption capability [4].

\section{Mechanism of Capacitive Deionization Membrane (MCDI)}

Capacitive deionization membrane (MCDI) is the application of cell voltage technology to the desalination of water between two opposite configured porous carbohydrate electrodes. The ion-exchange membrane is placed before each electrode, and there is a spacer between them; which carries the water to be desalinated. Water can flow against each other from the electrons through the segment of the membrane spacing. Ions are separated from the feed water and temporarily stored in the electrical double layers (EDLs) of the carbon-electrode electrode interface [10]. The electrodes will be regenerated until they are filled with ions, and the applied cell voltage can be reduced or even reversed [4]. After the ions are released from the electrodes, the waste stream can now be flushed out of the space. Upon regeneration of the elements, the system is ready to remove ions from the feed water [11]. Figure 2(a), Figure 2(b) shows the movement of feed water within the electrode with and without membrane for CDI system [12].

In 2006, the addition of Ion Interchange Membrane (IEM) located before electrodes, which is known as membrane capacitive deionization (MCDI) (Figure 3(b)), is significant improvements over traditional CDI [13]. This addition of (IEM) represent the main difference between CDI and MCDI; where the MCDI cell architecture designed to enhance the performance of capacitive deionization (CDI) cell by positioning the ion-exchange membrane in front of each electrode (cation exchange membrane (CEM) near the cathode and a cation exchange 


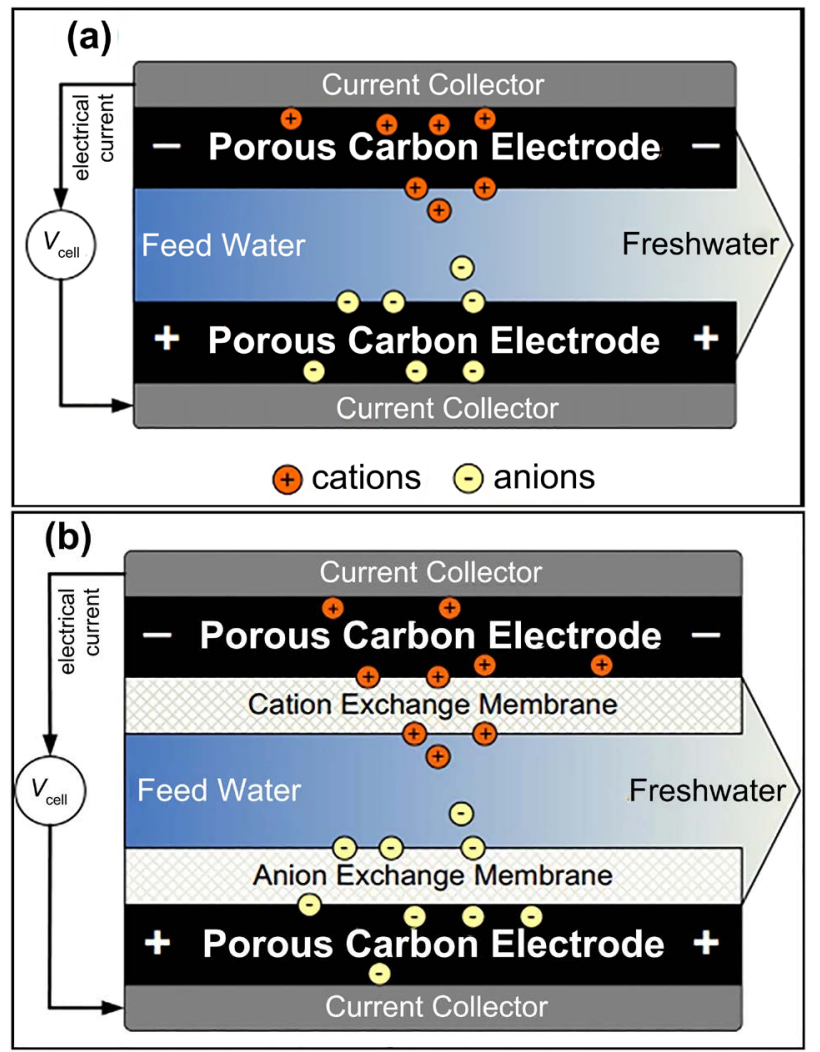

Figure 2. (a) Capacitive deionization (CDI), [12]. (b) Capacitive Deionization Membrane (MCDI), [12].

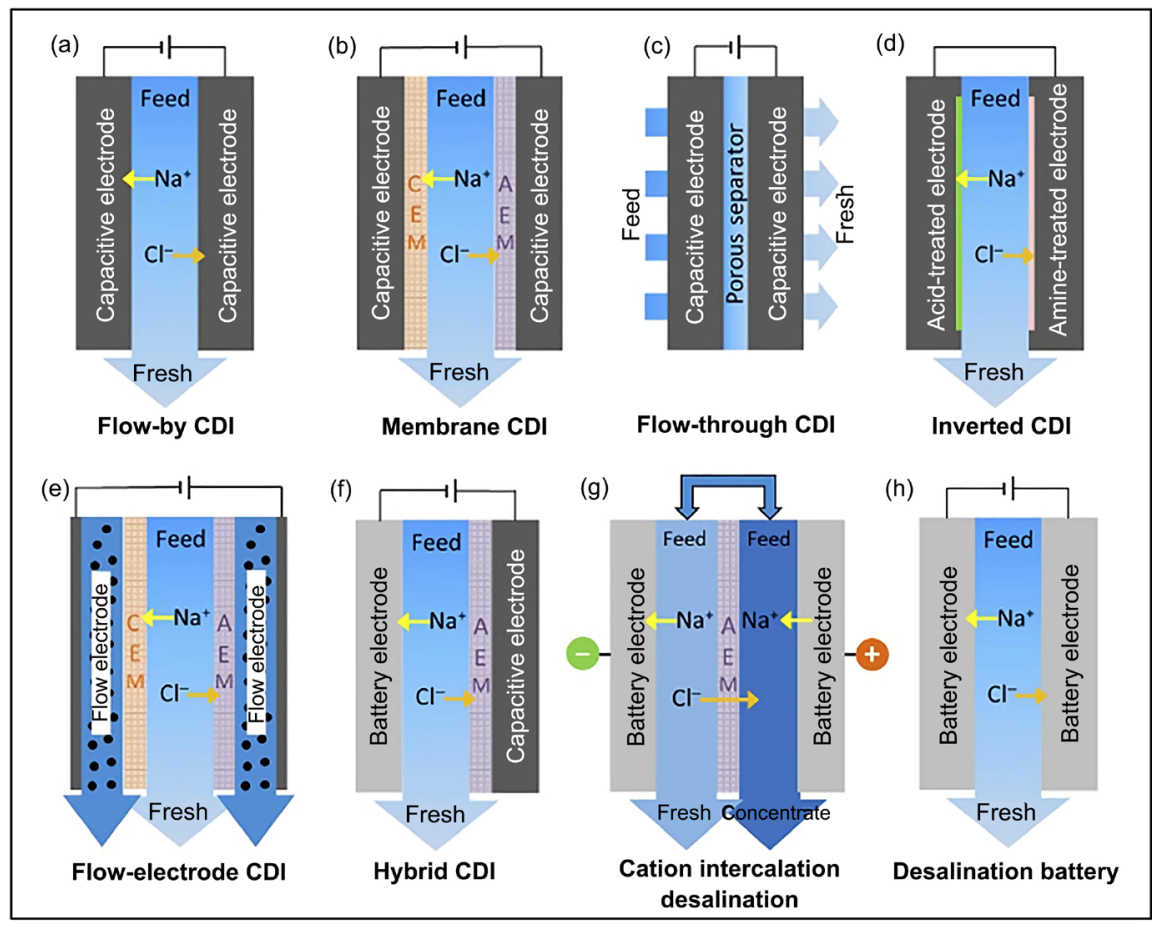

Figure 3. Typical cell architectures of various CDI: (a) Flow-by CDI, (b) Membrane CDI, (c) Flow-through CDI, (d) Inverted CDI, (e) Flow-electrode CDI, (f) Hybrid CDI, (g) Cationinte calation desalination, and (h) Desalination battery [13]. 
membrane (AEM) near the anode). Membranes block the respective co-ions from carrying parasitic current which contributes to improved load efficiency and increased salt storage in electrode macropores [14]. In specific, the cathode is adjacent to the cation exchange membrane (CEM) and a cation exchange membrane (AEM) is located adjacent to the anode. Co-ions are expelled from micropores while charging, but cannot penetrate the IEMs and thus remain in the electrode macropores. Since the macropores are still electrically neutral, they can be used as an external storage room for counterfeits and thus boost the efficiency of ion removal [6].

The use of IEMs in typical CDIs is also an efficient means of increasing electrode life by preventing direct water scoring and reducing specific Faradaic reactions [15]. (M)CDI cells can be assembled to create a stack in several pairs in order to optimize the ion removal efficiency for realistic applications. These stacks may be related to fluid flow in parallel or in sequence after they have been packed into a box and sealed. In parallel with ion desorption, one of the strong advantages of CDI relative to other desalinization technologies can be partly retrieved and used for charging an additional (M)CDI cell that works in the ion adsorption stage, in the energy deposited on an energy storage medium, such as the super capacitor, for future use [16].

\section{Perspective and Electrode Materials}

The fast increase in maximum salt adsorption capacity (mSAC) may be the most relevant pathway for future research in capacitive CDI electrode materials by optimizing CDI electron materials and pore structure. (see the blue cycles, Figure 4).

The design requires careful balance of the criteria for rapid transport of ions to micropores (for example, at molecular diffusion rates), high micro-porosity, and rapid transport of ions in micropores. In general, the efficient transfer of ions to micropores is assured by positioning these micropores in a network of

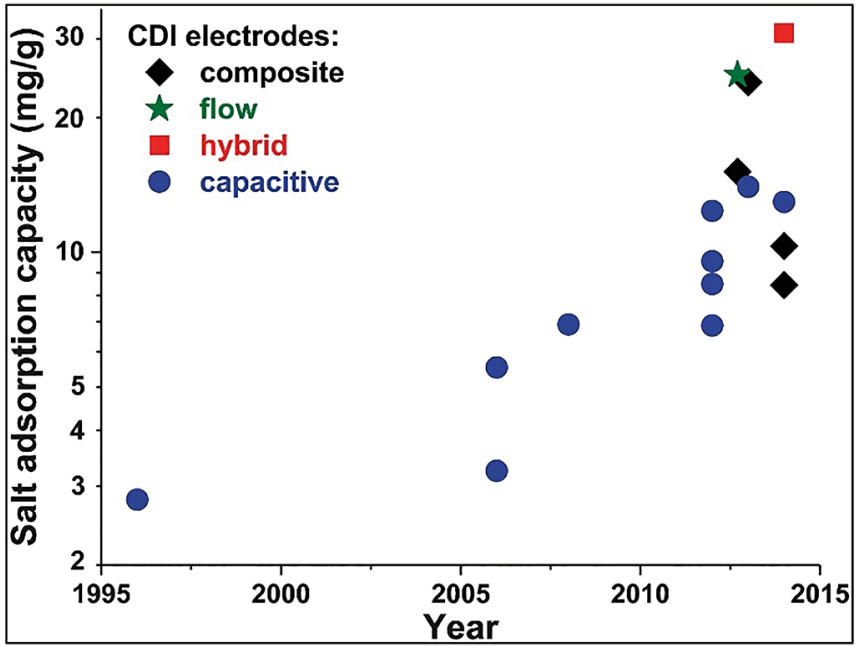

Figure 4. Record of maximum capacity for salt adsorption (mSAC) [14]. 
macropores by electrodes. The design requires careful balance of the criteria for rapid ion transfer to micropores (for example, at molecular diffusion rates), high micro-porosity, and rapid ion transport in micropores. In general, the efficient transport of ions to micropores is assured by positioning these micropores in a network of macropores by electrodes. Future work will, however, decide the optimal network structure and pore size of the macropore which enables rapid transport; but also, the maximum amount of micropore (max. salt storage). Monolithic materials are particularly promising as inert binder materials are not used; which absorbs weight, does not move or store ions, and therefore it is necessary for work to improve these electrode materials further. By the way, we can see that adding a conduction additive is only helpful if the current density of the super capacitor unit is sufficiently high during the charging process. Usually, the use of conductive additives results in a lower mSAC value, as the activated carbon is mixed with a material with tiny pores. Key performance information should therefore preferably be applied to the electrode as a whole.

\section{Applications for CDI Present and Future}

The development, quality and understanding of flow electrodes (slurry-electrodes) are another significant research path for CDI in future. In order to improve water recovery, higher hydraulic pressure is needed on the RO. Due to the increased water recovery, however, the efficiency of extraction could be reduced as the feed solution is concentrated [14]. Optimization difficulties and RO-system efficiency have led to the development of the new MCDI technology, which demonstrates a high level of efficiency in the removal and improved energy efficiency [7]. While flow electrode architectures allow high salinity feed to be desalinated, Electron transport is actually significantly affected by them relative to static electrodes. Although the influence of pore dispersion on Salt sorption is extensively studied, its impact on Electrode microcro-structure (e.g. binding spheres to monolithic Ver-sus fibers) has not yet been fully determined and elucidated with regard to efficiency. The use of capacitive deionization (CDI) was most commonly studied and used to desalination brackish water to provide drinking or farm water. Current CDI systems may require less energy in low-level salt desalination (around an order less than and in magnitude than seawater), Compared with existing desalination technologies such as reverse osmosis (RO) and MSF. CDI, is a technology that, as an electrodialysis, directly transports (relatively small) salt ions from feed water instead of removing (full) Salt water ions, such as RO and MSF molecules. For CDI, dissolved salts a semi-permeable membrane is transported in which salt ions remain largely on the surface of the membrane. The energy requirement for CDI is therefore significantly determined by the concentration of salt ion in feed water and has a lower RO ratio. The energy needs of MCDI and RO were compared in Reference [16] with a salt concentration cross-over below which MCDI is more energy efficient (about 2 $\mathrm{g} / \mathrm{L} 1$ ). The CDI static electrode systems (Figures 5(a)-(f)) have been characterized 


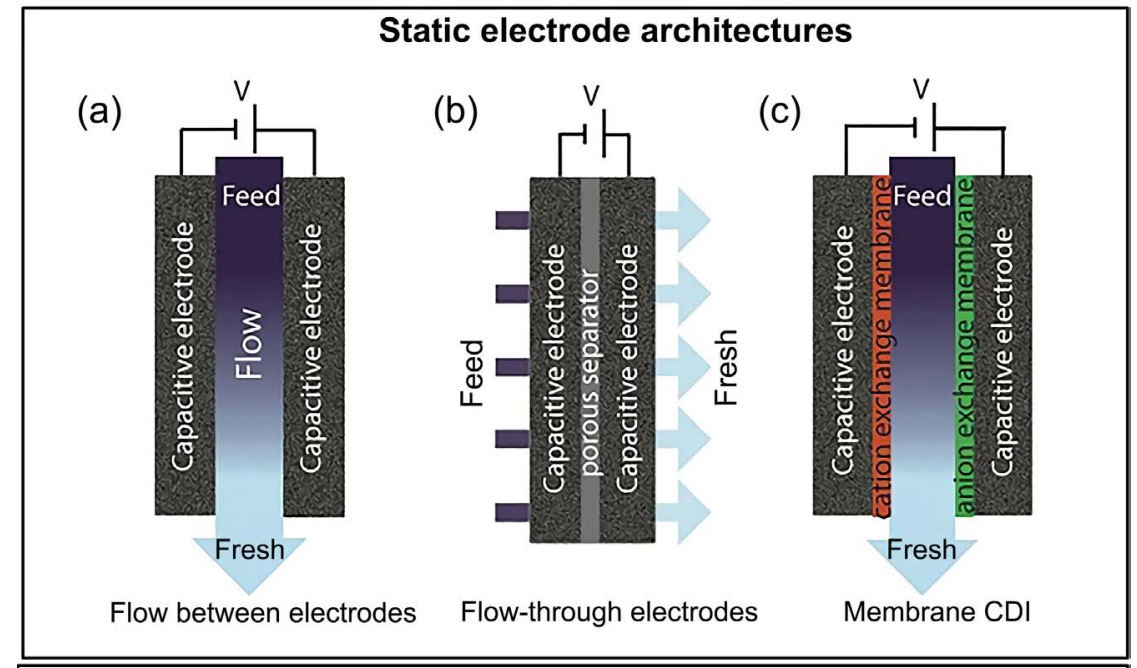

(d)

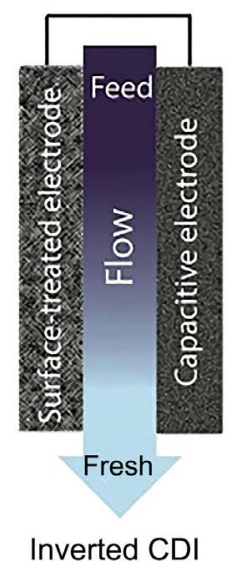

(e)

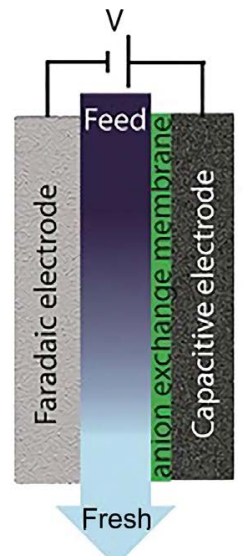

Hybrid CDI (f)

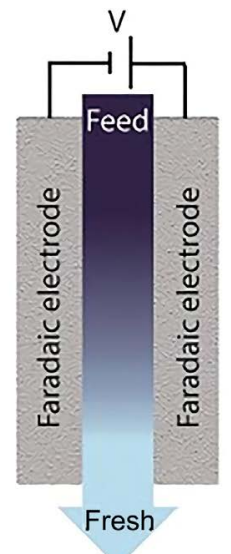

Desalination battery

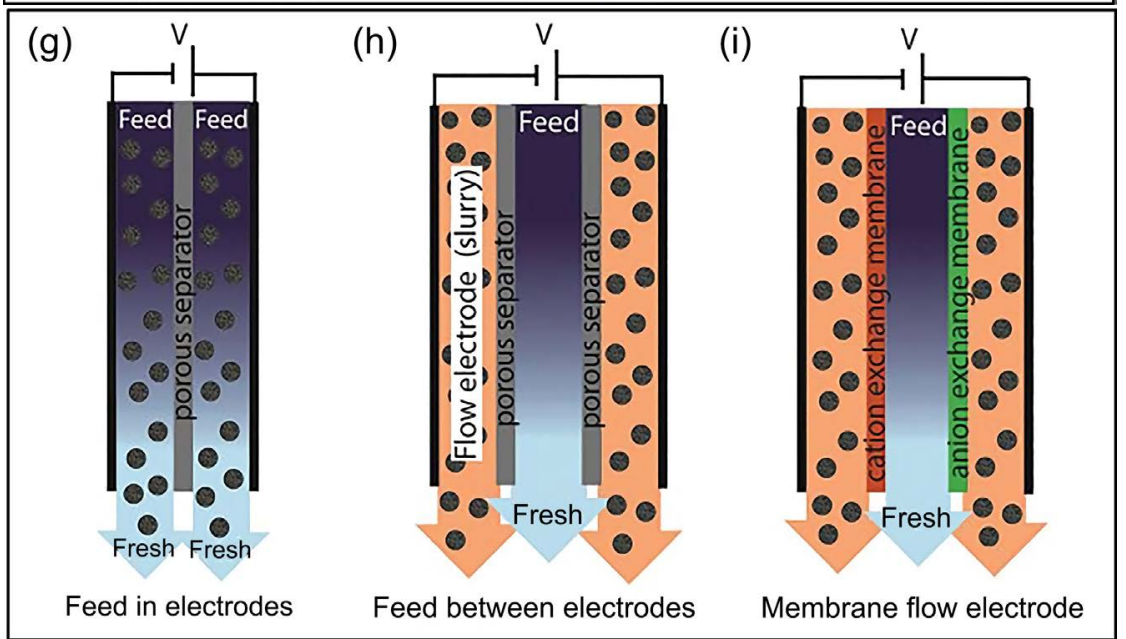

Figure 5. (a-f) The CDI static electrode systems [14].

by a small amount of salt adsorbed by a charge into a single Electrodeionization (EDI) is not possible in terms of infrastructure or energy (a ratio of 5:1 from electrode volume to the volume of water required for the proper desalination of marine waters) and, as a result, marine desalination with static dry-water CDI 
systems is not feasible. The overwhelming majority of CDI laboratory experiments use brackish feed water to test new cell or electrode architectures.

\section{Opportunity of Using CDI and MCDI on Desalination}

Capacitive deionization flow-by (CDI) and capacitive deionization membrane (MCDI) are the two most common cell architectures in the use of CDI for water treatment. A remarkable number of advances have been observed with main aspects based on fabrics, operation, operating mode, cell architecture, Faradaic reactions and theoretical models [8]. With the recent introduction of the flow-electrode CDI (FCDI), hybrid CDI (HCDI), desalination batteries and CID cells, the CDI applications can be extended by the desalination of sea water; where the FCDI cell is the result of modifying the MCDI cell using flowing carbon suspension electrodes instead of stationary electrode between existing collectors and IEMs, and was first proposed by Jeon et al. in 2013 [18]. As an alternative to second pass for sea water treatment plant, capacitive membrane, Deionization. A two-pass RO cycle is thus widely used for treating RO with brackish water reverse osmosis (BWRO), to satisfy the water quality criteria [19]. Nevertheless, BWRO's auxiliary usage increases energy consumption considerably (e.g. BWRO at desalination plant in Perth, Australia, $0.35 \mathrm{kWh} / \mathrm{m}^{3}$ ) [14]. However, due to an increase in water recovery, the processing capacity could be decreased as the feed solution is condensed. Consequently, the difficulties in optimizing the RO process and its versatile operation led to the development of a new desalination technology. Capacitive deionization CDI, which provides a professional extraction efficiency and improved power output. CDI has been investigated for a wide range for applications such as brackish desalination of water, water suppression and ultrapure water treatment. With the advent of the cation pair and anion exchange membrane (called MCDI) CDI process, the efficiency of desaltification and loading is significantly improved by avoiding co-ion transport [14]. The main advantages of MCDI are Low energy consumption, low impacts on climate, high water recovery with total dissolved solids (TDS) below 400 for brackish water treatment. Applied innovative solutions using MCDI technologies in a range of desalination fields with and without RO Plant combined with a renewable energy source, hybrid systems, and RO for seawater combined with MCDI with EDR, provide an effective outcome. The latest membrane in CDI technology has been applied. Improving the saline and fouling problems also adds a new positive dimension to MCDI Technology. The following section explains the most recent and efficient experimental laboratory applied to MCDI technology.

\subsection{Second Pass for Seawater Desalination}

In this study, the viability of capacitive membrane deionization (MCDI) was considered to be one option for effective removal of bromide from the second BWRO pass. The study area, was taken place at Australia which Australian sur- 
face water consider to Relatively high bromide concentrations at an interval between 400 and $8000 \mathrm{mg} / \mathrm{l}$, with high concentration of seawater TDS between $60,000-78,000 \mathrm{mg} / \mathrm{l}$ [19]. Australian water standard highly regulated the maximum concentration of bromide to not exceed $20 \mathrm{mg} / \mathrm{l}$, for potable drinking water. As the reverse osmosis of seawater (SWRO) plays an important role in Australia's freshwater development. SWRO plants are usually used in Australia for an effective bromide removal through a 2nd pass brackish reverse water osmosis (BWRO). Figure 6 Schematic diagram of the processes of SWRO's second pass configuration and of the proposed (SWRO-MCDI) hybrid processes.

The research was performed by Wang L. et al., Basic principles of bromide extraction were systematically tested using the MCDI lab-scale. The process operated under varying water quality and operating conditions, and demonstrated that bromide can be successfully extracted from the MCDI TDS collection, which is normally connected to the SWRO 1st step of RO Pass [21]. The study finds out that; the energy consumption at a desalination plant in Perth in Australia for the second pass of the BWRO process is $0.35 \mathrm{kWh} / \mathrm{m}^{3}$, which is $40 \%$ higher than the energy consumption for the typical TDS feed of $300 \mathrm{mg} / \mathrm{L}$ with MCDI. In addition, the author recommended that, the kinetics of ions transfer to electricity via the surface of bromide ion should be improved effectively by enhancing ion selectivity through the use of this selectable resin in the ion exchange membrane. Furthermore, the energy consumption at a desalination plant in Perth in Australia for the second pass of the BWRO process is $0.35 \mathrm{kWh} / \mathrm{m}^{3}$, which is 40 percent higher than the energy consumption for the typical TDS feed of $300 \mathrm{mg} / \mathrm{L}$ with MCDI. Furthermore, the energy consumption in MDCI is directly linked to the feed water TDS. The energy efficiency of the feed water TDS is estimated to be less than $2000 \mathrm{mg} / \mathrm{L}$. Figure 7, shows the total energy consumption in MCDI when adsorbed and desorbed. The average working time was 2, 3 and 10 minutes with $1 \mathrm{~V}$ for feed water of 100, 200 and $300 \mathrm{mg} / \mathrm{L}$ TDS, with a processing time of 10 mins with $1.2 \mathrm{~V}$ for feed water of $400 \mathrm{mg} / \mathrm{L}$, respectively.

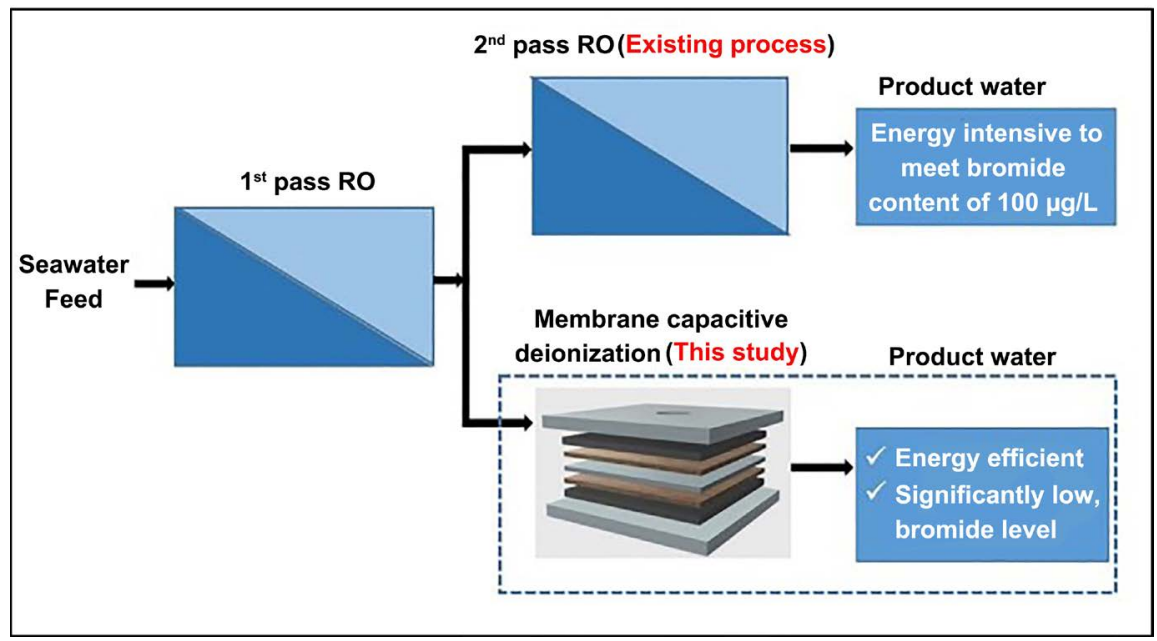

Figure 6. Schematic diagram of the processes of SWRO [20]. 


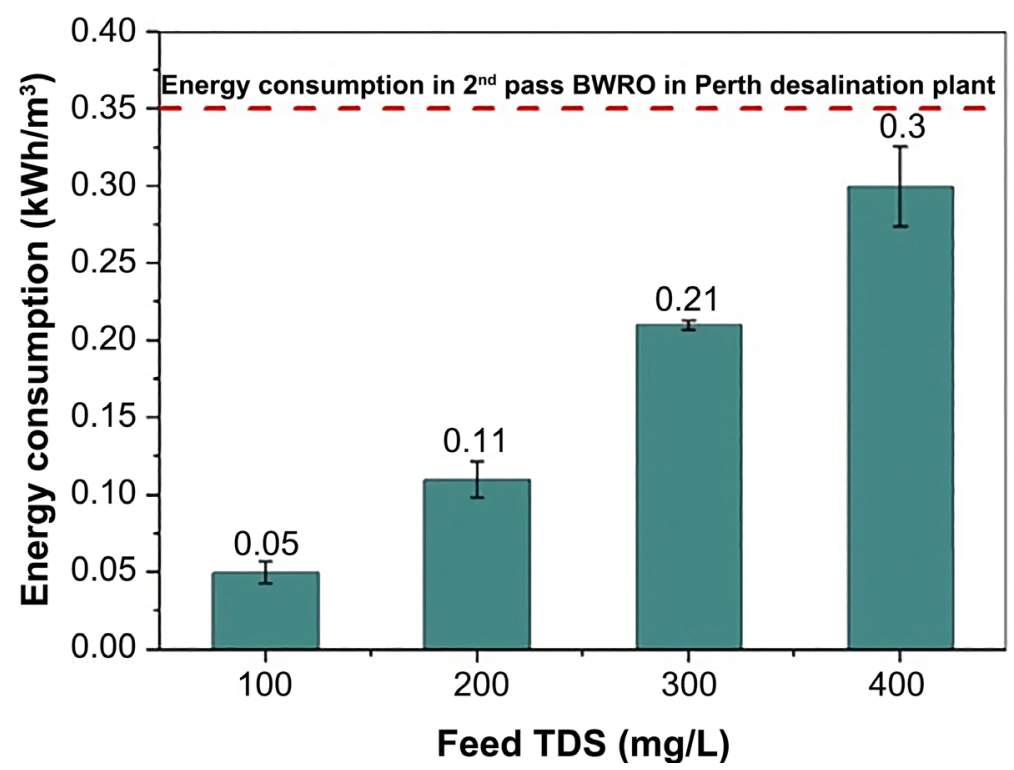

Figure 7. The total energy consumption in MCDI when adsorbed and desorbed [20].

In comparison, in Australia's Perth desalination facility the average power consumption of 2nd pass BWRO system was calculated at $40 \%$ higher than the average power requirement of $0.21 \mathrm{kWh} / \mathrm{m}^{3}$ for TDS of a feed of $300 \mathrm{mg} / \mathrm{L}$ with use of MCDI [20].

\subsection{Integration MCDI with PV-Solar Energy for Salt Removal from Brackish Waters}

Corresponding to a technology under the title (Integration of photovoltaic energy supply with capacitive membrane deionization (MCDI) for salt removal from brackish waters), introduced by Cheng Tan et al. [9]. The study, was conducted by a pilot prototype combining the MCDI system with solar photovoltaic as a source of energy [22]. The study covers a number of parameters, including the $\mathrm{PV}$-powered ( $5 \mathrm{~m}^{3} /$ day) MCDI system and the planning process for evaluating the critical elements of the renewable energy network. Designed and operating battery storage system. In addition, the energy analysis should include the power requirements of the auxiliary equipment. The charging current of the MCDI electrode(s) and the total average energy input from the PV device to the plant are critical design parameters. Model outputs are the number of panels, the battery capacity, the amount and the charging power of an electrode. Electric schemes and blocks See Figure 8(a) and Figure 8(b) for a description of the prototype experimental model. The study was carried out with the production and powerful MCDI technology using photovoltaic (PV) panels coupled with battery storage using a model equipment capable of charging currents of over $100 \mathrm{~A}$ and user volumes of five $\mathrm{m}^{3} /$ day. Guidelines are provided for the development of systems which can run without grid connection for 24 hours. The energy requirement for the MCDI model plant has been assessed and the relationship between the two parameters has been examined so that it can be used to dynamically adjust 


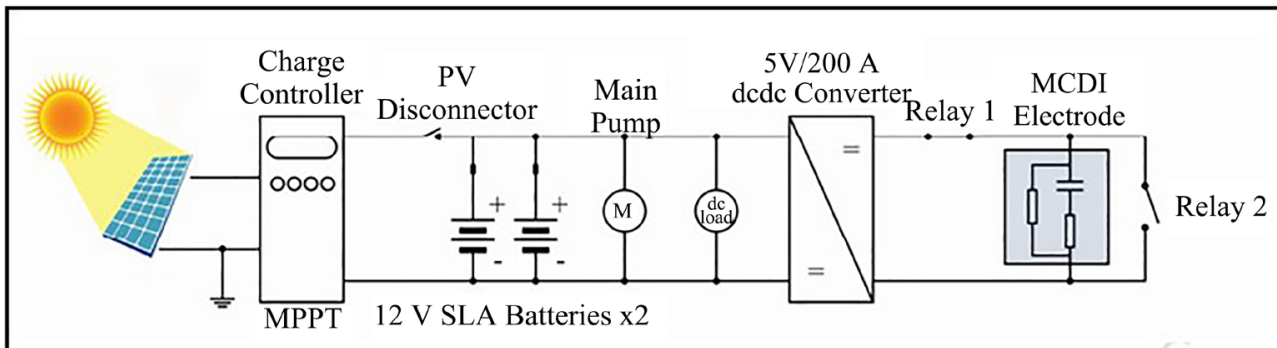

(a)

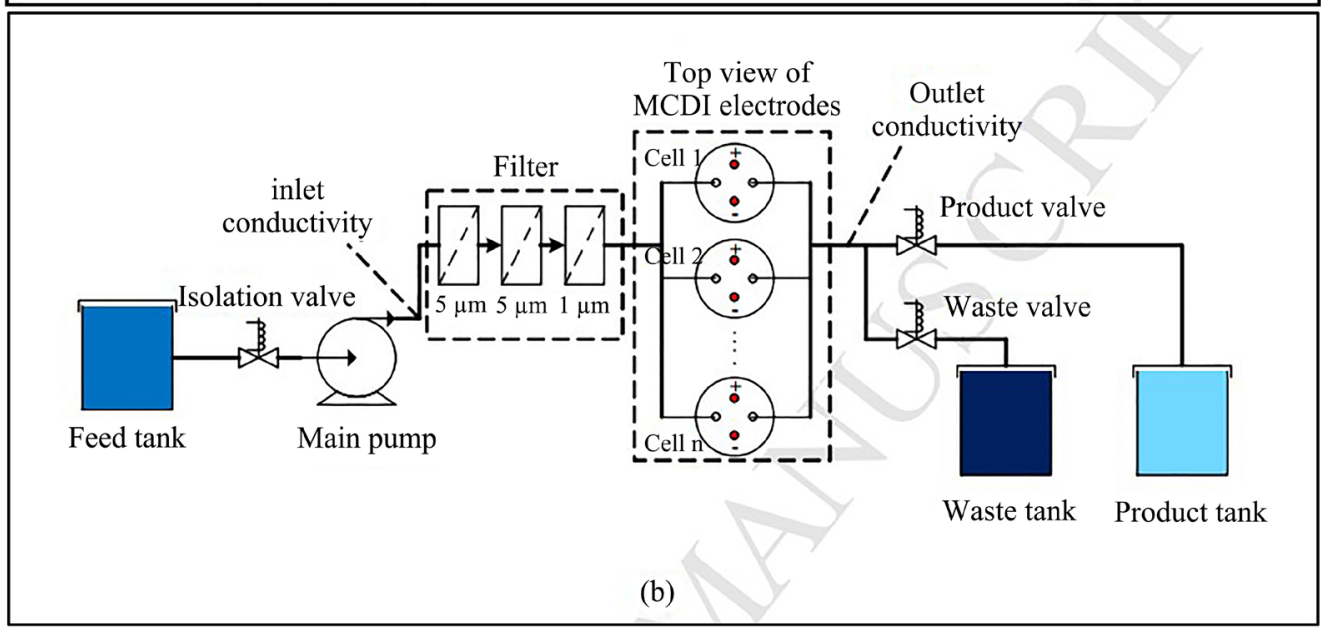

Figure 8. Schematic electric diagram and block diagram, the experimental prototype model see (a and b) diagram [9]. (a) Electrical Diagram schematic; (b) Block Diagram of the experimental layout of the prototype.

the working conditions of the system to increase the operating time of the built-in system controller.

In this study, there are three main important issues should also be considered to increase the potential benefits of MCDI technology. First of all, Ion exchange membranes are mounted before electrodes to facilitate the counter-transmission of the channel through the electrode and the coions are maintained within the structure of the electrode [17]. MCDI Electrode processing power can be recuperated and then reused by increasing the pilot plant's total energy consumption by at least $30 \%$. Such a reduction in energy consumption makes MCDI more energy efficient than other technologies. Second, MCDI can achieve a recovery rate of more than 80 per cent, which is difficult to achieve with RO. Although the experimental plant used in this study shows a peak water reclamation of 73, 2 percent, alternative methods of advanced desorption may be used for water reclamations of more than 80 percent. Thirdly, it can easily and accurately be accomplished with the change of the electrode charging current in MCDI. This management mode simplifies the system and reduces system costs accordingly. Lastly, the MCDI technique is scalable, because the system is adaptable to match the appropriate feed water and TDS material and adapts to various sources of energy including renewables. 


\subsection{MCDI-Reverse Electrodialysis (RED) Hybrid System for RO Seawater Desalination}

The last example of using the innovative technology of MCDI is a Hybrid system to improve the energy efficiency of RO seawater desalination. The study overtaking by Choi initially proposed a novel design that includes MCDI and RED in the treatment of high-salinity seawater, with an enhanced energy efficiency [7]. This study is based on the idea of integrating MDI and RED. In this hybrid system, MCDI effectively switches to BWRO and complies with the WHO specifications. RED has retained 33\% of its energy from discharges. RED also complies with the requirements for water quality. The RO hybrid method was found to be operating optimally at $0.8 \mathrm{~V}$ of the voltage applied at 50 percent and 80 percent of the water recovery for the first RO and second MCDI passes. The RO hybrid system operates efficiently and efficiently. In terms of both removal and energy efficiency, the study proposed RO-MCDI hybrid device has been investigated and made possible by two-pass ROs. The traditional two-pass RO system was used to treat seawater through the first RO pass and to further treat RO permeate through the second BWRO pass. Figure 9 Conceptual example of the (a) RO-MCDI-RED model two-pass hybrid systems and (b). In the RED step of RO and second-pass desalination, brine was used as HSS and LSS.

In this new hybrid model, since MCDI and RED both consume electrical energy, a minimum energy loss should be associated with the reversal of the energy compared to the two-pass integrated RO-RED system. Table 1 shows the approximate ranges of energy demands for various desalination technologies.

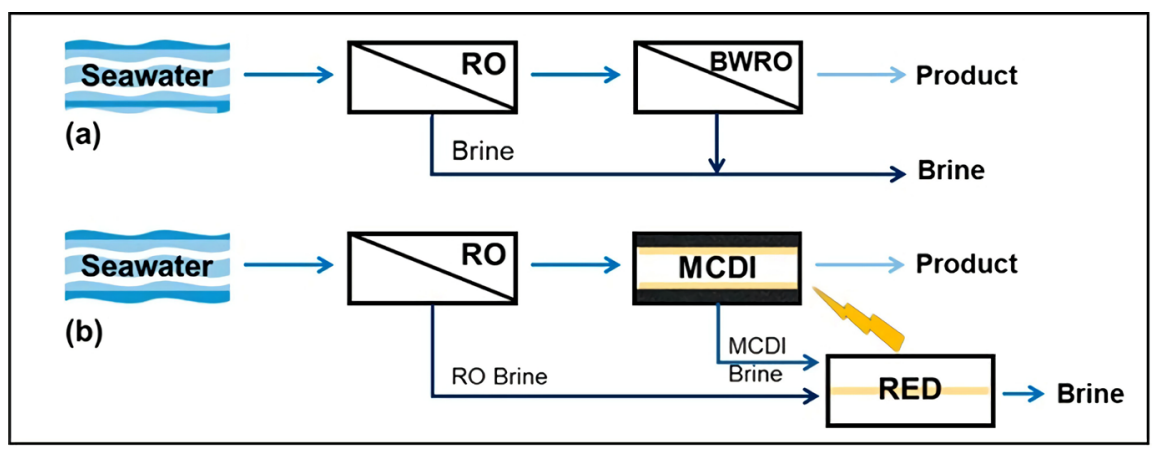

Figure 9. Conceptual example of the RO-MCDI-RED hybrid systems [19].

Table 1. The approximate ranges of energy demands for various desalination technologies. Adapted from Refs. [23]-[29].

\begin{tabular}{cc}
\hline Technology & Energy demand $\left(\mathrm{kWh} / \mathrm{m}^{3}\right)$ \\
\hline MSF & $10-58$ \\
MED & $6-58$ \\
RO & $2-6$ \\
ED & $0.4-8.7$ \\
CDI & $0.1-2.03$ \\
\hline
\end{tabular}


MCDI is the device that uses an effective renewable energy system made from photovoltaic panels, stand-alone systems and battery storage. Although a few studies have yet to examine in depth the ability of MCDI to be used in conjunction with the use of alternative energy sources. Due to low power consumption, low pressure; RO and low temperatures; MCDI technologies should seem sufficient for thousands of liters of distilled hourly water from brackish waters in contrast to distillation. The MCDI method for salt removal can be derived from data on concentrations of effluent salt and current electricity versus time, Information on the specific energy use as a result of the concentration of influential salt in experimental settings on a laboratory scale was presented and compared to the RO data reported in the full-scale RO desalination plant literature. Research on MCDI in the lower concentration range, less than $60 \mathrm{mM}$, has been demonstrated [16].

\subsection{Integration of CDI with a Bioelectrochemical System}

Bioelectrochemical device as a microbial fuel cell (MFC) and microbial desalination

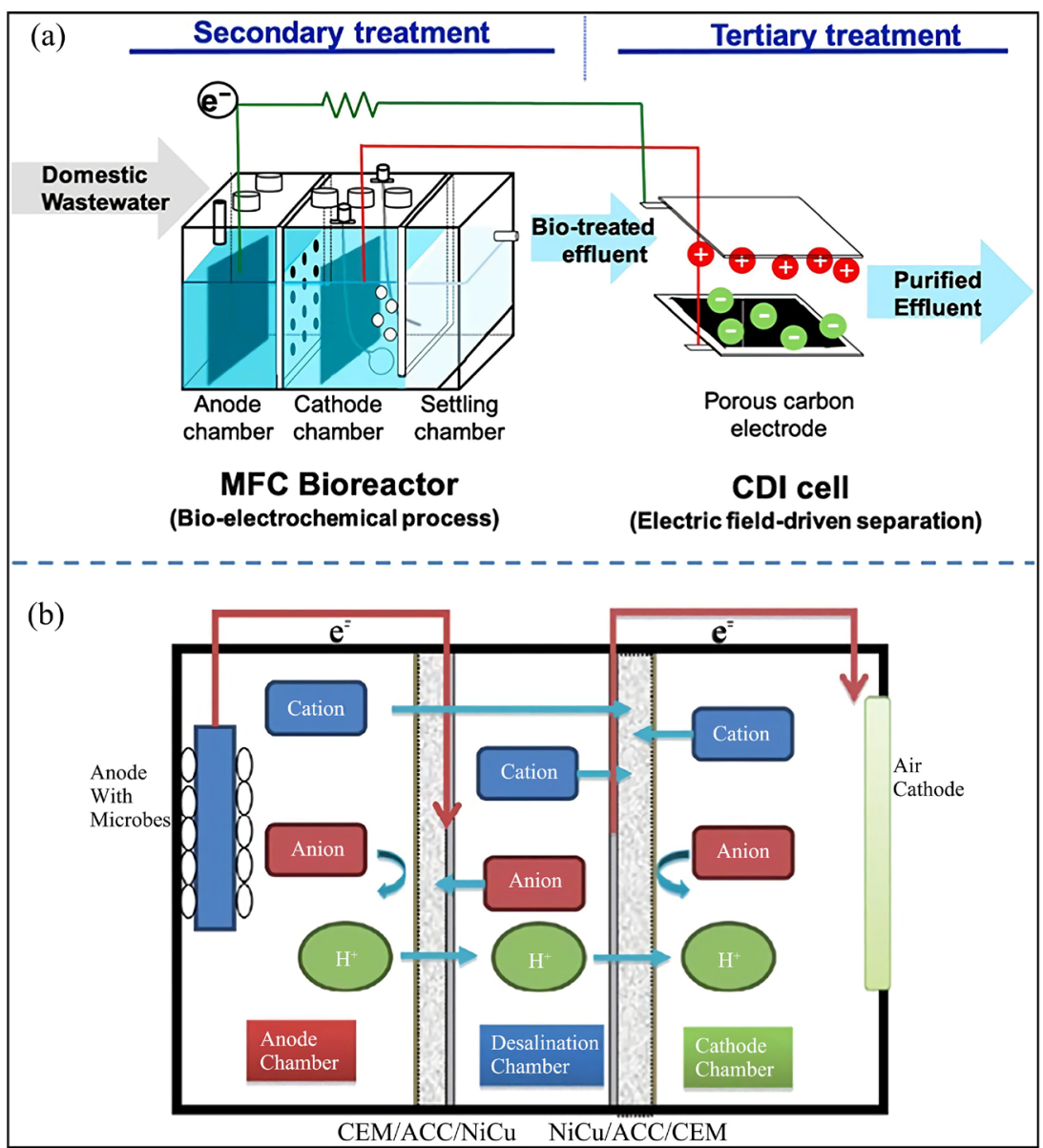

Figure 10. (a) Schematic design of the coupled MFC-CDI system for the simultaneous removal of organic contaminants, desalination and electricity generation. Reproduced with permission from Ref. [32], (b) Schematic of a microbial capacitive desalination cell (MCDC). Reproduced with permission from Ref. [33]. 
cell (MDC). MFC is an advanced technique that uses exo-electrogenic micro-organisms to oxidize organic matter in wastewater to generate electricity [33]. The low voltage requirement of CDI can be used to power the CDI for the downstream deionization phase, allowing simultaneous removal of organic matter or salinity, as well as for production of electricity, from continuous flow MFCs. See Figure 10(a), Figure 10(b) [35]. MDC is a new technology which can desalinate water in the middle chamber between anode and cathode through the electrical potential produced by microorganisms during organic degradation for ion transportation through a couple of CEM and AEM products as a derivative of MFCs [34]. However, MDC suffered a pH fluctuation and the resulting anolyte and catholyte solutions were condensed with desalination chamber salt, which makes them unsuitable for many reuse applications [35].

\section{Conclusions and Recommendation}

The challenges in optimizing the multiple-faceted application of the RO system have led to an analysis of the current MCDI desalination technique; which provides efficient retrieval and enhanced power efficiency. MCDI technology has addressed a variety of applications; e.g. desalination of brackish water, softening of water, and processing of ultrapure water. MCDI consumes low energy, has low environmental impacts and has a high level of water recovery while treating brackish water below $4000 \mathrm{mg} / \mathrm{L}$ with a TDS level, which is the most important benefit of the MCDI system. In addition, the study evaluated the related technologies and, therefore, a number of important recommendations should be considered in future studies, summarized as follows:

- Sodium chloride solution is most commonly found in drinking water in deionized water. These latter conditions require careful, and controlled tests for proof-of-concept work, but not all of them during continuous treatment of real brackish water.

- Bromide removal may be further improved by using the MCDI approach in contrast to use a special bromide-selective ion-exchange membrane to add anion exchanger membrane in current research.

- In contrast with other desalination plants, the MCDI is efficient in applications where photovoltaic is the only energy source. Through enhancing optimization, process construction and advanced water recovery techniques, the system quality can be further enhanced.

- A substantial stability of the MCDI's removal efficiency may produce significant synergistic results with RED which would lead to increased energy efficiency.

- The proposed hybrid system RO-MCDI-RED has shown better energy efficiency compared to an RED two-pass RO system; however, the progress made in both MCDI and RED is expected to make further improvements.

- Therefore, with respect to the traditional two-pass RO system, RED's novel RO-MCDI-RED hybrid system reduced respectively energy consumption, by 39.0 per cent and even by 16.8 per cent under optimized terms. Many tech- 
niques have been developed to reduce the energy consumption of the MCDI system. One is the recovery of energy during the desorption, which achieved highly efficient results.

- This finding suggested that further processes of desalination were needed to satisfy the World Health Organization (WHO) TDS concentration standards. In order to achieve a proper disposal and energy efficiency, MCDI has been introduced on behalf of BWRO as the second pass desalination protocol.

\section{Acknowledgements}

The authors would like to acknowledge Oxfam-OPTI "WASH Program" for "the award" funded by and European Commission (EU).

\section{Conflicts of Interest}

The authors declare no conflicts of interest regarding the publication of this paper.

\section{References}

[1] Tang, W.W., Wang, X.X., Zeng, G.M., Liang, J., Li, X.D., Xing, W.L., He, D., Tang, L. and Liu, Z.F. (2019) Electro-Assisted Adsorption of Zn (II) on Activated Carbon Cloth in Batch-Flow Mode: Experimental and Theoretical Investigations. Environmental Science \& Technology, 53, 2670-2678.

https://doi.org/10.1021/acs.est.8b05909

[2] McNair, R., Cseri, L., Szekely, G. and Dryfe, R. (2020) Asymmetric Membrane Capacitive Deionization Using Anion-Exchange Membranes Based on Quaternized Polymer Blends. ACS Applied Polymer Materials, 2, 2946-2956.

https://doi.org/10.1021/acsapm.0c00432

[3] Yong, L., Pana, L., Xua, X., Lua, T., Zhuo, S. and Chua, D.H.C. (2014) Enhanced Desalination Efficiency in Modified Membrane Capacitive Deionization by Introducing Ion-Exchange Polymers in Carbon Nanotubes Electrodes. Electrochimica Acta, 130, 619-624. https://doi.org/10.1016/j.electacta.2014.03.086

[4] Porada, S., Zhao, R., van der Wal, A., Presser, V. and Biesheuvel, P.M. (2013) Review on the Science and Technology of Water Desalination by Capacitive Deionization. Progress in Materials Science, 58, 1388-1442.

https://doi.org/10.1016/j.pmatsci.2013.03.005

[5] Subramani, A., Badruzzaman, M., Oppenheimer, J. and Jacangelo, J.G. (2011) Energy Minimization Strategies and Renewable Energy Utilization for Desalination: A Review. Water Research, 45, 1907-1920.

https://doi.org/10.1016/j.watres.2010.12.032

[6] Suss, M.E., Porada, S., Sun, X., Biesheuvel, P.M., Yoonf, J. and Presser, V. (2015) Water Desalination via Capacitive Deionization: What Is It and What Can We Expect from It? Energy \& Environmental Science, 8, 2296-2319. https://doi.org/10.1039/C5EE00519A

[7] Choi, J., Dorji, P., Shon, H.K. and Hong, S. (2019) Applications of Capacitive Deionization: Desalination, Softening, Selective Removal, and Energy Efficiency. Desalination, 449, 118-130. https://doi.org/10.1016/j.desal.2018.10.013

[8] Tang, W., Liang, J., He, D., Gong, J.L., Tang, L., Liu, Z.F., Wang, D.B. and Zeng, G.M. (2019) Various Cell Architectures of Capacitive Deionization: Recent Ad- 
vances and Future Trends. Water Research, 150, 225-251. https://doi.org/10.1016/j.watres.2018.11.064

[9] Tan, C., He, C., Tang, W.W., Kovalsky, P., Fletcher, J. and David Waite, T. (2018) Integration of Photovoltaic Energy Supply with Membrane Capacitive Deionization (MCDI) for Salt Removal from Brackish Waters. Water research, 147, 276-286. https://doi.org/10.1016/j.watres.2018.09.056

[10] Bales, C., Kovalsky, P., Fletcher, J. and David Waite, T. (2019) Low Cost Desalination of Brackish Groundwaters by Capacitive Deionization (CDI)_-Implications for Irrigated Agriculture. Desalination, 453, 37-53.

https://doi.org/10.1016/j.desal.2018.12.001

[11] Qin, M., Deshmukh, A., Epsztein, R., Patel, S.K., Owoseni, O.M., Shane Walker, W. and Elimelech, M. (2019) Comparison of Energy Consumption in Desalination by Capacitive Deionization and Reverse Osmosis. Desalination, 455, 100-114. https://doi.org/10.1016/j.desal.2019.01.003

[12] Długołęcki, P. and van der Wal, A. (2013) Energy Recovery in Membrane Capacitive Deionization. Environmental Science \& Technology, 47, 4904-4910. https://doi.org/10.1021/es3053202

[13] Lee, J.B., Park, K.K., Eum, H.M. and Lee, C.W. (2006) Desalination of a Thermal Power Plant Wastewater by Membrane Capacitive Deionization. Desalination, 196, 125-134. https://doi.org/10.1016/j.desal.2006.01.011

[14] Choi, J., Oh, Y., Chae, S. and Hong, S. (2019) Membrane Capacitive Deionization-Reverse Electrodialysis Hybrid System for Improving Energy Efficiency of Reverse Osmosis Seawater Desalination. Desalination, 462, 19-28. https://doi.org/10.1016/j.desal.2019.04.003

[15] Alkuran, M., Orabi, M. and Scheinberg, N. (2008) Highly Efficient Capacitive Deionization (CDI) Water Purification System Using a Buck-Boost Converter. 2008 23rd Annual IEEE Applied Power Electronics Conference and Exposition, Austin, 24-28 Feburary 2008, 1926-1930. https://doi.org/10.1109/APEC.2008.4522991

[16] Zhao, R., Porada, S., Biesheuvel, P.M. and van der Wal, A. (2013) Energy Consumption in Membrane Capacitive Deionization for Different Water Recoveries and Flow Rates, and Comparison with Reverse Osmosis. Desalination, 330, 35-41. https://doi.org/10.1016/j.desal.2013.08.017

[17] Biesheuvel, P.M., Zhao, R., Porada, S. and van der Wal, A. (2011) Theory of Membrane Capacitive Deionization Including the Effect of the Electrode Pore Space. Journal of Colloid and Interface Science, 360, 239-248. https://doi.org/10.1016/j.jcis.2011.04.049

[18] Jeon, S.I., Park, H.R., Yeo, J.G., Yang, S., Cho, C.H., Han, M.H. and Kim, D.K. (2013) Desalination via a New Membrane Capacitive Deionization Process Utilizing Flow-Electrodes. Energy \& Environmental Science, 6, 1471-1475. https://doi.org/10.1039/c3ee24443a

[19] Dorji, P., Choi, J., Kim, D.I., Phuntsho, S., Hong, S. and Shon, H.K. (2018) Membrane Capacitive Deionisation as an Alternative to the 2nd Pass for Seawater Reverse Osmosis Desalination Plant for Bromide Removal. Desalination, 433, 113-119. https://doi.org/10.1016/j.desal.2018.01.020

[20] Al Marzooqi, F.A., Al Ghaferi, A.A., Saadat, I. and Hilal, N. (2014) Application of Capacitive Deionisation in Water Desalination: A Review. Desalination, 342, 3-15. https://doi.org/10.1016/j.desal.2014.02.031

[21] Wang, L., Wang, M., Huang, Z.H., Cui, T., Gui, X., Kang, F., Wang, K. and Wu, D. (2011) Capacitive Deionization of $\mathrm{NaCl}$ Solutions Using Carbon Nanotube Sponge 
Electrodes. Journal of Materials Chemistry, 21, 18295-18299. https://doi.org/10.1039/cljm13105b

[22] Çetinkaya, A.Y. (2020) Life Cycle Assessment of Environmental Effects and Nitrate Removal for Membrane Capacitive Deionization Technology. Environmental Monitoring and Assessment, 192, Article No. 543.

https://doi.org/10.1007/s10661-020-08501-0

[23] Welgemoed, T.J. and Schutte, C.F. (2005) Capacitive Deionization Technology ${ }^{\mathrm{Tm}}:$ An Alternative Desalination Solution. Desalination, 183, 327-340. https://doi.org/10.1016/j.desal.2005.02.054

[24] Farmer, J.C., Fix, D.V., Mack, G.V., Pekala, R.W. and Poco, J.F. (1996) Capacitive Deionization of $\mathrm{NaCl}$ and $\mathrm{NaNO}_{3}$ Solutions with Carbon Aerogel Electrodes. Journal of the Electrochemical Society, 143, 159-169. https://doi.org/10.1149/1.1836402

[25] Biesheuvel, P.M. and Bazant, M.Z. (2010) Nonlinear Dynamics of Capacitive Charging and Desalination by Porous Electrodes. Physical Review E, 81, Article ID: 031502. https://doi.org/10.1103/PhysRevE.81.031502

[26] Turek, M. (2003) Cost Effective Electrodialytic Seawater Desalination. Desalination, 153, 371-376. https://doi.org/10.1016/S0011-9164(02)01130-X

[27] Farmer, J.C., Fix, D.V., Mack, G.V., Pekala, R.W. and Poco, J.F. (1996) Capacitive Deionization of $\mathrm{NH}_{4} \mathrm{ClO}_{4}$ Solutions with Carbon Aerogel Electrodes. Journal of Applied Electrochemistry, 26, 1007-1018. https://doi.org/10.1007/BF00242195

[28] American Water Works Association (1917) M46 Reverse Osmosis and Nanofiltration: Manual of Water Supply Practices. 2nd Edition, American Water Works Association, Denver, 1917.

[29] Peters, T.A. (1999) Desalination of Seawater and Brackish Water with Reverse Osmosis and the Disc Tube Module DT. Desalination, 123, 149-155.

https://doi.org/10.1016/S0011-9164(99)00068-5

[30] Feng, C.J., Hou, C.H., Chen, S.H. and Yu, C.P. (2013) A Microbial Fuel Cell Driven Capacitive Deionization Technology for Removal of Low Level Dissolved Ions. Chemosphere, 91, 623-628. https://doi.org/10.1016/j.chemosphere.2012.12.068

[31] Xing, W., Liang, J., Tang, W.W., He, D., Yan, M., Wang, X.X., Luo, Y., Tang, N. and Huang, M. (2020) Versatile Applications of Capacitive Deionization (CDI)-Based Technologies. Desalination, 482, Article ID: 114390.

https://doi.org/10.1016/j.desal.2020.114390

[32] Feng, C., Tsai, C.C., Ma, C.Y., Yu, C.P. and Hou, C.H. (2017) Integrating Cost-Effective Microbial Fuel Cells and Energy-Efficient Capacitive Deionization for Advanced Domestic Wastewater Treatment. Chemical Engineering Journal, 330, 1-10. https://doi.org/10.1016/j.cej.2017.07.122

[33] Forrestal, C., Xu, P. and Ren, Z.Y. (2012) Sustainable Desalination Using a Microbial Capacitive Desalination Cell. Energy \& Environmental Science, 5, 7161-7167. https://doi.org/10.1039/c2ee21121a

[34] Ma, D., Forrestal, C., Ji, M., Li, R., Ma, H. and Ren, Z.J. (2015) Membrane Configuration Influences Microbial Capacitive Desalination Performance. Environmental Science: Water Research \& Technology, 1, 348-354.

https://doi.org/10.1039/C5EW00003C

[35] Stoll, Z.A., Forrestal, C., Ren, Z.J. and Pei, X. (2015) Shale Gas Produced Water Treatment Using Innovative Microbial Capacitive Desalination Cell. Journal of Hazardous Materials, 283, 847-855. https://doi.org/10.1016/j.jhazmat.2014.10.015 